\title{
Sistema de Avaliação Didática Acessível Portátil para Pessoas com Deficiência Visual: estudo de caso com a plataforma Android
}

\author{
Ana Grasielle Dionísio Corrêa, Patrícia Araújo de Oliveira, Laisa Caroline Costa \\ De Biase, Danilo Leite Damon, Roseli de Deus Lopes
}

Laboratório de Sistemas Integráveis - Escola Politécnica da Universidade de são Paulo Av. Prof. Luciano Gualberto, travessa 3, nº 158 - 05508-970 - São Paulo - SP - Brasil

\{anagrasi, paaraujo, laisa, danilo, roseli\}@lsi.usp.br

\begin{abstract}
The availability of mobile devices, such as tablets, to students and teachers, make M-Learning a viable option, fostering changes in how subjects consume and create content knowledge. However, the access to these features by the visually impaired is not assured. The design of applications must allow the access to all individuals (universal design). In this work, we present an educational assessment system for tablets to be used by both students with and without visual impairments. The application includes a survey in a QUIZ format, with two modes of operation: test and exam. Seven visual impaired students evaluated positively the application for educational purposes.
\end{abstract}

Resumo. A distribuição de dispositivos móveis, como tablets, para alunos e professores, viabiliza o M-Learning, impulsionando mudanças na forma como os sujeitos se relacionam com a informação e produzem conhecimento. Contudo, o acesso aos recursos nestes dispositivos, por pessoas com deficiência visual, pode não garantir acessibilidade. O design dos aplicativos deve permitir o acesso a todos os indivíduos (design universal), independente de possuir ou não algum tipo de deficiência. Neste trabalho, apresentamos um sistema de avaliação didática acessível para tablets para uso por alunos com ou sem deficiência visual. $O$ sistema apresenta um questionário com perguntas e respostas em formato QUIZ e inclui dois modos de utilização: Teste e Prova. O sistema foi avaliado por sete alunos com deficiência visual, o que indicou que está adequado para uso com fins educacionais.

\section{Introdução}

A Organização Mundial de Saúde (OMS) estima que 285 milhões de pessoas em todo o mundo possuem deficiência visual: 39 milhões são cegos e 246 milhões têm baixa visão [WHO, 2013]. Segundo a OMS, cerca de 19 milhões de crianças, em idade escolar, são cegas ou têm baixa visão. $80 \%$ dessas crianças vivem em países em desenvolvimento onde, apenas uma a cada dez crianças, tem acesso à educação. Entre as causas dessa desigualdade podemos citar a falta de professores qualificados e materiais apropriados, falta de conhecimento dos pais sobre o direito de todos à educação e limitação de políticas públicas e interesse político. 
O processo de aprendizagem dos alunos cegos ocorre através das informações táteis, auditivas e sinestésicas que recebem do ambiente [Silva et al., 2013]. Esses alunos não são diferentes de seus colegas que enxergam no que diz respeito ao desejo de aprender, à curiosidade, às motivações, às necessidades gerais de cuidados, brincadeiras, limites, convívio e recreação, dentre outros aspectos relacionados à formação da identidade e aos processos de desenvolvimento e aprendizagem. Portanto, devem ser tratados como qualquer educando no que se refere aos direitos, deveres, normas, regulamentos, disciplina e demais aspectos da vida escolar [Sá et al., 2007].

A inclusão desses alunos na sala de aula ocorre por meio de materiais adaptados, tais como mapas, gráficos e ilustrações em relevo, maquetes, brinquedos, livros em Braille, Tecnologias Assistivas (TAs), entre outros [Bazon, 2012]. TAs são recursos e serviços que contribuem para proporcionar ou ampliar habilidades funcionais de pessoas com deficiência e, consequentemente, promover uma vida independente.

A Secretaria de Educação Especial (Seesp) do Ministério da Educação (MEC) têm proposto ações para que as TAs cheguem às escolas, disponibilizando materiais específicos para alunos com deficiência visual [Rosito e Scariot, 2012]: livros adaptados, livros em Braille, computadores equipados com leitores de tela, teclados e mouses especiais, etc. O esforço do MEC, agora, é incluir tablets no ensino por um custo mais baixo, como fez com o programa Um Computador por Aluno (UCA). A intenção é que todos os professores e alunos, da rede pública de ensino, tenham seu próprio tablet para uso em sala de aula [Real et al., 2013]. Contudo, a inserção dos tablets no processo de ensino e aprendizagem pode tornar-se um ponto de segregação de alunos com deficiência visual. Apesar do potencial que estes dispositivos possuem para ajudar pessoas com deficiência visual a ler, navegar, se comunicar e interagir com o meio [Machado et al., 2014], ainda há uma carência muito grande no número de aplicações educacionais acessíveis.

Este estudo tem por objetivo apresentar o desenvolvimento de um sistema de avaliação didática acessível portátil para tablets e os resultados dos testes de usabilidade realizados com alunos com deficiência visual. O desenvolvimento seguiu os princípios do Design Universal, o que possibilitou garantir sua utilização por alunos com e sem deficiência visual. Inicialmente, são apresentados os fundamentos que nortearam o desenvolvimento deste trabalho. Em seguida, é apresentada a interface do sistema, desenvolvido para Android, e suas principais funcionalidades. Em sequência, é apresentada a metodologia e os resultados da avaliação de usabilidade com alunos com deficiência visual. Por último, são apresentadas as conclusões da pesquisa.

\section{Fundamentação Teórica}

\subsection{Deficiência Visual}

De acordo com a Classificação Internacional de Doenças CID-10 (OMS CID-10, 2001), existem quatro níveis de função visual: visão normal, deficiência visual moderada, deficiência visual grave e cegueira. Deficiência visual moderada combinada com deficiência visual grave é denominada "baixa visão". Baixa visão, em conjunto com a cegueira, representa a deficiência visual. Determina-se, portanto, dois grupos: 
- Cegueira: há perda total da visão ou pouquíssima capacidade de enxergar, o que leva a pessoa a necessitar do Sistema Braille como meio de leitura e escrita.

- Baixa visão: caracteriza-se pelo comprometimento do funcionamento visual dos olhos, mesmo após tratamento ou correção. As pessoas com baixa visão podem ler textos impressos ampliados ou com uso de recursos óticos especiais.

\subsection{Uso de Tablets no Ensino}

Uma pesquisa realizada por Shuler (2009) apontou a elevada quantidade de horas que é dispensada por crianças, a partir dos oito anos de idade, com dispositivos eletrônicos (smartphones, tablets, computadores, games, etc.). Esse fenômeno vem despertando o interesse de pesquisadores e educadores sobre as vantagens e desvantagens do uso destas tecnologias para o ensino. De acordo com Shuler (2009), uma das vantagens do uso de dispositivos móveis na educação é a possibilidade de aprender em qualquer lugar e em qualquer momento: paradigma de ensino denominado "Mobile Learning ( $M$ learning)". M-learning vem sendo discutida há muito tempo, ganhando força no Brasil em 2005, com a implantação do programa Um Computador por Aluno (UCA). Desde então, inúmeros estudos envolvendo professores e estudantes com uso dos laptops têm surgido na literatura com apontamentos que evidenciam os benefícios desta tecnologia para apoiar o aprendizado [Menezes et al., 2013; Venâncio et al., 2008]. O esforço agora é complementar o aparato tecnológico existente nas escolas com a distribuição de tablets para alunos como material de apoio pedagógico permanente.

Vários relatos e pesquisas no Brasil, envolvendo escolas de Ensino Fundamental e Médio e investigações internacionais, apontam o impacto signigficativo do uso dos tablets na Educação. Heinrich (2012), por exemplo, constatou que os alunos demonstraram grande aceitação no uso de tablets para realizar atividades de pesquisa, comunicação e colaboração. Segundo o autor, o aumento da motivação na sala de aula reflete também nos professores que estão aproveitando cada vez mais o arsenal de aplicativos disponíveis. Real et al. (2013) analisaram as modificações frente à prática pedagógica de professores e alunos com o uso dos tablets no ensino. Segundo os autores, apesar da resistência de alguns professores que reclamam das políticas públicas na Educação, as capacitações são um fator provocativo para muitos professores, levando-os a desejarem aprender como usar o tablet em sala de aula com seus alunos.

\subsection{Uso de Tablets por pessoas com Deficiência Visual}

Apesar do crescente esforço para desenvolver e aplicar TAs no ensino de pessoas com deficiência visual [Rosito e Scariot, 2012] e, apesar do crescimento do uso de tablets em propostas de ensino [Real et al., 2013], o uso desta tecnologia por deficientes visuais ainda é limitado. Há ainda muito que se investigar sobre a forma de utilização dos tablets por alunos com deficiência visual sem que sejam necessárias grandes adaptações e diferenciações de uso quando comparado aos alunos videntes. A maioria das investigações está na busca de soluções para um grupo particular de usuários cegos [DOSVOX, 2015; Santos et al., 2012; Silveira e Martini, 2011; Albernaz, 2011].

Diversas diretrizes e recomendações vêm sendo implementadas e avaliadas [Machado et al., 2014; Filho et al., 2012]. Todas essas soluções e pesquisas são muito importantes, uma vez que as telas sensíveis ao toque estão se tornando comuns na 
interação do homem com as tecnologias atuais. Não é apenas importante o fato das pessoas cegas terem o acesso a elas, mas também que elas possam fazer uso destas telas de forma eficiente e eficaz [Filho et al., 2012].

Usuários cegos têm maior sensibilidade tátil em seus dedos do que as pessoas com visão normal [Filho et al., 2012]. Por essa razão, a utilização de tablet por esse público pode ser bastante promissor, uma vez que a exploração por toque possibilita o acesso sem intermediação de um mouse ou de outro dispositivo de entrada de dados e potencializa a construção de um mapa mental da área de navegação. Esta ação é facilitada pela existência de uma referência física do dispositivo móvel, possibilitando identificar o início, o meio e o fim da tela, o que facilita a localização dos elementos da interface [Machado et al., 2014].

Os tablets oferecem recursos de acessibilidade para ajudar usuários com deficiência visual a interagir mais facilmente. Tablets Android, por exemplo, disponibilizam: text-to-speech (voz automatizada que lê os elementos dispostos na tela); feedback tátil (vibração); navegação por toques, duplo toques e gestos (um, dois ou três dedos); digitação falada através do teclado QWERTY; zoom; texto aumentado; cores invertidas e reconhecimento de voz. Todos esses recursos, aliados às recomendações de usabilidade, tais como as de Nielsen e Badiu (2012), ajudam a construir aplicações acessíveis para usuários com deficiência visual.

\section{Desenvolvimento do Sistema de Avaliação Didática Acessível Portátil}

O protótipo do Sistema de Avaliação Didática Acessível Portátil assemelha-se a um questionário com perguntas e respostas em formato QUIZ. O protótipo é constituído por três tipos de telas: a) tela de apresentação contendo instruções de navegabilidade (Figura 1a); b) tela de pergunta contendo uma pergunta e cinco opções de respostas de múltipla escolha (Figura 1b); c) tela de resultado contendo o resultado final (Figura 1c).

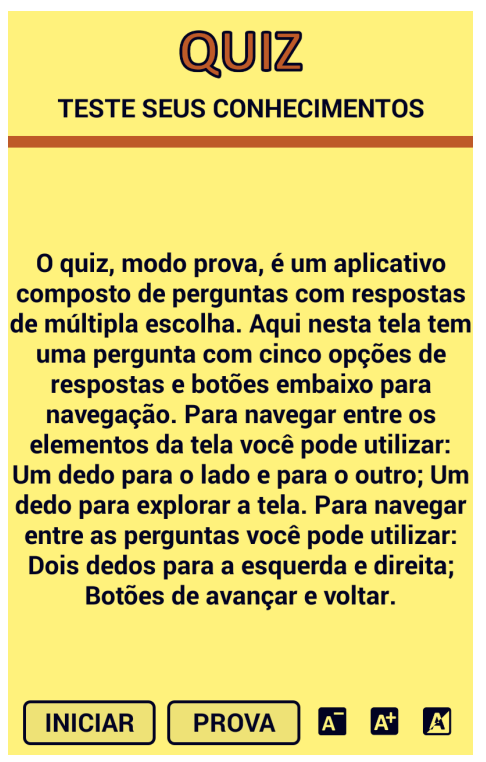

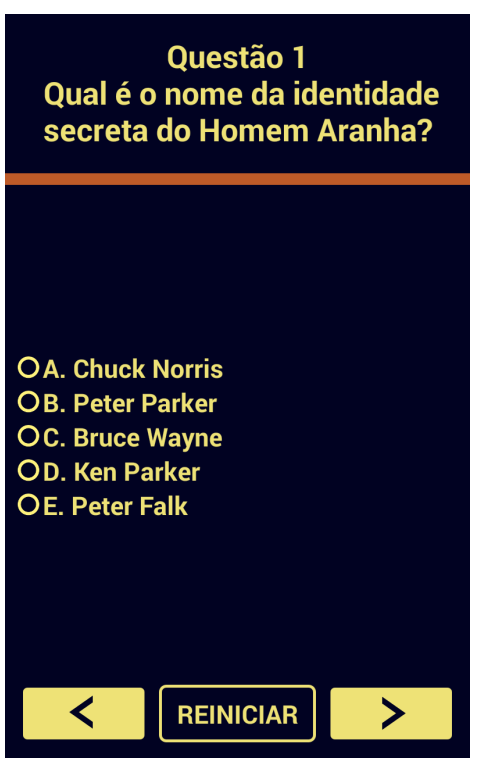

Figura 1. Telas do QUIZ

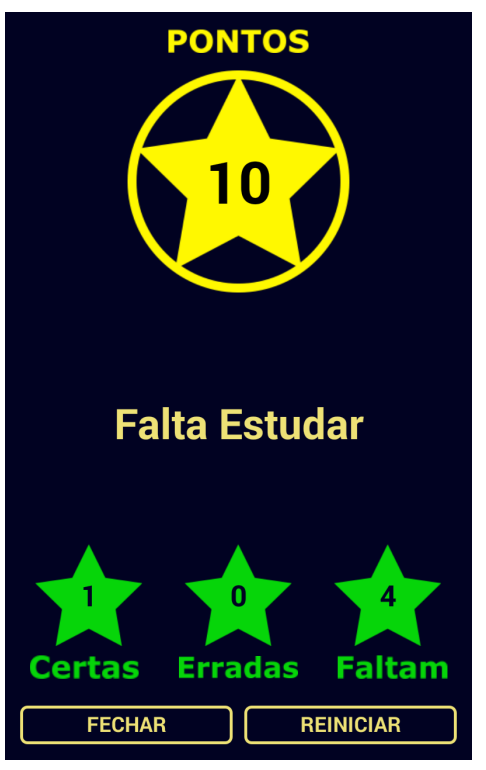

Falta Estudar

A Tela de apresentação possui um texto com instruções de navegabilidade e um menu de navegação composto de botões: "Iniciar"; selecionar o modo de utilização 
"Teste" ou "Prova"; "diminuir/aumentar a fonte"; e "Inverter cores". A função de inverter as cores de fundo e texto é uma opção de acessibilidade para os usuários com baixa visão. Quando o botão "Inverter cores" estiver ativado, a tela fica semelhante a um negativo de foto (Figura $1 b$ ).

A Tela de Perguntas é constituída de uma pergunta com cinco opções de respostas de múltipla escolha e um menu de navegação que varia segundo o modo de utilização (Teste ou Prova). A Tela de Resultado mostra a pontuação do usuário. Cada pergunta correta soma 10 pontos no resultado final. Se a pontuação final estiver entre: $70 \%$ e $100 \%$ de acertos, é apresentada uma mensagem "EXCELENTE"; entre $30 \%$ e $69 \%$ de acertos, a mensagem é "BOM"; entre $0 \%$ e $29 \%$ de acertos, a mensagem é "PODE MELHORAR". Além disso, a tela de resultado mostra a quantidade de respostas certas e erradas e a quantidade de questões que não foram respondidas. E ainda os botões "Fechar" que encerra a aplicação e "Reiniciar" que reinicia o QUIZ e redireciona o usuário para a tela de apresentação.

O protótipo QUIZ possui dois modos de utilização: Modo Teste e Modo Prova. O Modo Teste possui o botão “Avançar" que permite que o usuário avance as perguntas. Não é permitido voltar para as perguntas anteriores, pois após a escolha de uma das opções de respostas é fornecido o feedback imediato de acerto ou erro da questão. Por este motivo, o botão "Voltar" foi excluído deste modo de utilização. O feedback de seleção da questão é composto de um background colorido e um aviso sonoro. No caso de acerto, o background visual é verde com aviso sonoro de acerto. Caso contrário, o background visual é vermelho com um aviso sonoro de erro.

O QUIZ Modo Prova, além do botão "Avançar", possui o botão "Voltar" que foi adicionado para possibilitar a navegação entre as perguntas, ou seja, o usuário pode voltar para a tela de pergunta anterior. Consequentemente, o feedback de acerto/erro não é fornecido ao usuário, após a seleção de uma das alternativas. Assim, o usuário tem o controle e a liberdade para mudar a resposta.

\section{Testes com Usuários com Deficiência Visual}

O objetivo do estudo foi investigar a usabilidade do QUIZ quando utilizado por pessoas com deficiência visual. Testamos a seguinte hipótese: "pessoas com deficiência visual são capazes de realizar avaliações didáticas através de um questionário acessível com questões de múltipla escolha em dispositivos com interface touchscreen?".

\subsection{Metodologia}

Os testes foram realizados no Instituto de Cegos Padre Chico em São Paulo. Participaram dos testes 7 alunos com deficiência visual categorizados em dois grupos: Grupo A (cegueira total) e Grupo B (baixa visão). Cada participante realizou o teste individualmente acompanhado de um avaliador e um observador. $\mathrm{O}$ teste teve duração média de 40 minutos por participante, sendo os primeiros 15 minutos de treinamento.

Primeiro cada participante foi entrevistado pelo avaliador, por meio de um Questionário de Perfil de Usuário, a fim de obter informações acerca da deficiência visual e experiências com tecnologias. De posse do Roteiro de Tarefas, o avaliador realizou o teste enquanto o observador coletou dados sobre o desempenho dos participantes: sucesso e tempo para execução de cada tarefa e detalhes observados. Por 
último, o participante respondeu, por meio de entrevista, o Questionário de Satisfação da Interação a fim de obter dados subjetivos sobre a interação com o aplicativo. Esta pesquisa foi aprovada pelo Comitê de Ética em Pesquisa do Hospital Universitário da Universidade de São Paulo (HU/USP), sob o protocolo n ${ }^{0} 191.937$.

Antes de iniciar os testes, foi necessário realizar um treinamento com os participantes, a fim de familiarizá-los com o QUIZ. Foi utilizado um protótipo "Aprendizagem QUIZ" como apoio. Denominamos esta etapa de "Fase de Aprendizagem", pois os participantes "aprenderam" os Mecanismos de Interação (MI) para interagir com o aplicativo. Os MIs apresentados foram:

1. Dois toques com um dedo sobre a tela para selecionar um elemento.

2. Explorar a tela com um toque para ouvir as informações da tela.

3. Deslizar um dedo para direita ou esquerda para ouvir as informações da tela.

4. Deslizar dois dedos para a direita ou esquerda para mudar de tela.

Os testes com o QUIZ foram divididos em duas partes: navegação entre alternativas (Teste A) e navegação entre perguntas (Teste B). O Teste A é composto por tarefas para leitura e seleção/desseleção das respostas (Tabela 1). Primeiro os participantes realizavam as tarefas através do MI2 e, depois, as mesmas tarefas foram executadas através do MI3. Por último, foi solicitado que o participante executasse novamente as mesmas tarefas com o MI de sua preferência. Participantes do Grupo B (baixa visão), antes de iniciar os testes, foram convidados a ajustar o contraste de cores entre fundo e texto e o tamanho da fonte.

O Teste B é composto por tarefas para navegação entre as perguntas (navegação entre as telas). Inicialmente as tarefas foram executadas através do MI4 e, depois, as mesmas tarefas foram executadas com auxílio dos botões de navegação "Avançar" e "Retroceder". Neste caso, os usuários ficaram livres para decidir como acessar os botões: utilizando MI2 ou MI3. Por último foi solicitado que o participante executasse novamente as mesmas tarefas com o MI de sua preferência.

Tabela 1. Tarefas do QUIZ

\begin{tabular}{|c|c|}
\hline Tarefas - Teste A & Mecanismos de Interação (MI) - Teste A \\
\hline \multirow{3}{*}{$\begin{array}{l}\text { Configurar o tamanho da fonte e } \\
\text { contraste (apenas baixa visão) } \\
\text { - Ler a pergunta } \\
\text { - Navega entre as alternativas } \\
\text { - Seleciona a alternativa A } \\
\text { - Ler a pergunta novamente } \\
\text { - Seleciona a alternativa D } \\
\end{array}$} & MI2 - Explorar a tela com um toque. \\
\hline & MI3 - Deslizar um dedo para direita ou esquerda. \\
\hline & Escolhe a forma que desejar (MI2 ou MI3). \\
\hline Tarefas - Teste B & Mecanismos de Interação (MI) - Teste B \\
\hline \multirow{3}{*}{$\begin{array}{l}\text { - Avança para a próxima pergunta } \\
\text { - Retorna duas perguntas } \\
\text { - Avança uma perguta } \\
\text { - Retorna mais duas perguntas } \\
\text { - Avança duas perguntas }\end{array}$} & MI4 - Deslizar dois dedos para a direita ou esquerda. \\
\hline & MI2/MI3 - Usando os botões avançar e retroceder \\
\hline & Escolhe a forma que desejar botões de navegação MI4 ou botões. \\
\hline
\end{tabular}

O Questionário de Satisfação da Interação (Tabela 2) foi aplicado no final de cada Teste, A e B, com perguntas acerca da satisfação da interação e respostas variando segundo a escala de Likert (Muito Fácil / Fácil / Indiferente / Difícil / Muito Difícil). As 
perguntas 1, 2 e 3 foram feitas para todos os participantes. As perguntas 4, 5 e 6, do Teste A, foram feitas apenas para os participantes do Grupo B (baixa visão).

Tabela 2. Questionário de Satisfação da Interação

\begin{tabular}{|c|l|l|}
\hline & \multicolumn{1}{|c|}{ Pergunta pós Teste A } & \multicolumn{1}{|c|}{ Perguntas pós Teste B } \\
\hline 1 & $\begin{array}{l}\text { O que achou de navegar entre as alternativas } \\
\text { deslizando um dedo para direita ou esquerda? }\end{array}$ & $\begin{array}{l}\text { O que achou de navegar entre as perguntas utilizando o } \\
\text { gesto de deslizar dois dedos para a direita ou esquerda? }\end{array}$ \\
\hline 2 & $\begin{array}{l}\text { O que achou de navegar entre as alternativas } \\
\text { explorando a tela com o toque? }\end{array}$ & $\begin{array}{l}\text { O que achou de navegar entre as perguntas utilizando os } \\
\text { botões? }\end{array}$ \\
\hline 3 & $\begin{array}{l}\text { Você prefere navegar entre as alternativas } \\
\text { deslizando o dedo ou explorando com o toque? }\end{array}$ & $\begin{array}{l}\text { Você prefere navegar entre as perguntas por meio do } \\
\text { gesto ou botões? }\end{array}$ \\
\hline 4 & $\begin{array}{l}\text { O que achou de usar o tablet com o TalkBack } \\
\text { ativado? }\end{array}$ & \\
\hline 5 & $\begin{array}{l}\text { O que achou de usar o tablet lendo as informações } \\
\text { (contraste e cores alterados)? }\end{array}$ & \\
\hline 6 & $\begin{array}{l}\text { Você prefere usar o tablet com o TalkBack ativado } \\
\text { ou prefere ler as informações na tela a partir da } \\
\text { configuração do contraste e texto? }\end{array}$ & \\
\hline
\end{tabular}

\subsection{Resultados e Discussões}

\section{Perfil dos Participantes}

Os participantes possuem idade variando entre 11 e 16 anos, sendo três meninos e quatro meninas, cursando do 60 ao 80 ano. Todos são alfabetizados em Braille. Cinco possuem cegueira total (Grupo A) e dois possuem baixa visão (Grupo B). No Grupo A, apenas um dos participantes não possui computador em casa. Os demais utilizam computadores, com frequência moderada (uma vez por semana), com o software DOSVOX, jogos e chats. Três dos participantes já utilizaram celulares e tablets, mas preferem o computador como tecnologia de comunicação e entretenimento. No Grupo $\mathrm{B}$, apenas um dos participantes não possui computador em casa. Todos os outros utilizam computadores, com frequência moderada, com o software DOSVOX instalado. Já utilizaram celulares e tablets, mas preferem computadores.

\section{Resultados do Grupo A (Cegueira Total)}

As Figuras $2 \mathrm{a}$ e $2 \mathrm{~b}$ mostram a porcentagem de acertos e erros dos Testes A e B, respectivamente. Tanto no Teste $\mathrm{A}$ quanto no Teste $\mathrm{B}$, o número de acertos foi muito maior que o número de erros. Na forma livre, o total de erros é praticamente inexistente. Os erros identificados se justificam pelo fato de que alguns participantes não lembraram os movimentos aprendidos na fase de aprendizagem. Supomos que seja pela falta de prática ou por não utilizarem a tecnologia touchscreen com frequência alta

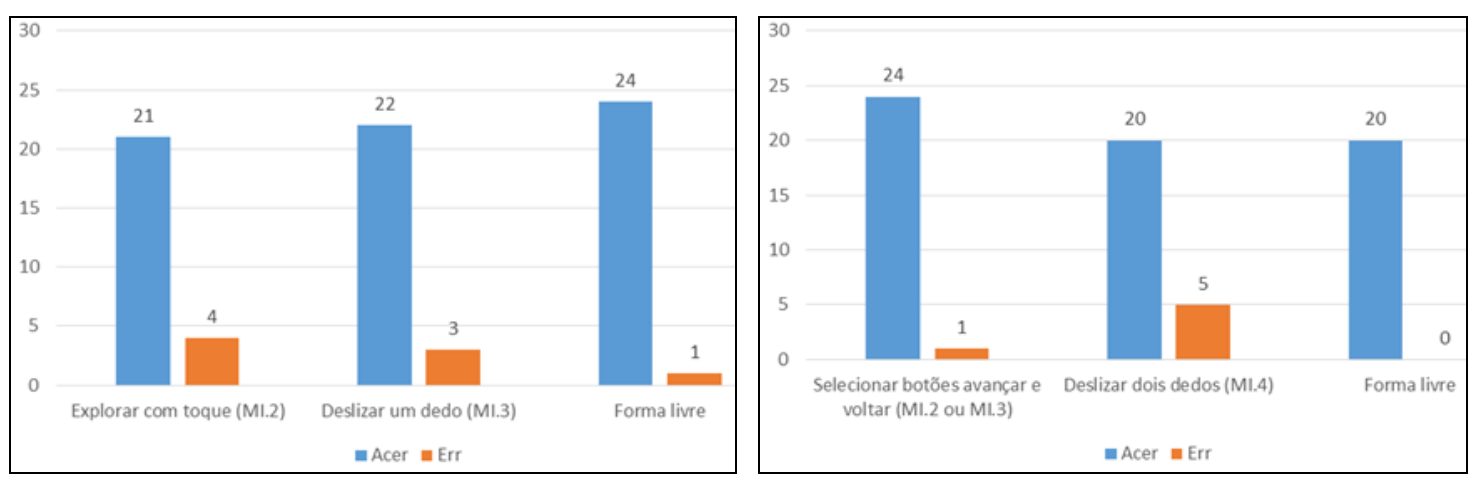

Figura 2. (a) Teste A; (b) Teste B 
As Figuras 3a e $3 \mathrm{~b}$ mostram o tempo médio para execução das tarefas dos Testes A e B, respectivamente. A tarefa 1 do Teste A "explorar com o toque" (MI2) foi mais demorada que a tarefa 2 "deslizar um dedo para direita ou esquerda" (MI3). Isso porque os participantes cegos esperavam o término da leitura da frase antes de avançar para o próximo elemento. Além disso, algumas vezes, eles tocavam em algum elemento intencionalmente. Quando isso acontecia, eles voltavam com o dedo no elemento anterior, recomeçando a leitura, e ouviam novamente a frase. Outros participantes não conseguiram manter o dedo sobre a tela para explorá-la. Neste caso, quando eles colocavam o dedo no elemento e a leitura da frase iniciava, imediatamente tiravam o dedo da tela, perdendo a referência de posicionamento dos elementos. Isso dificultava encontrar o próximo elemento da tela.
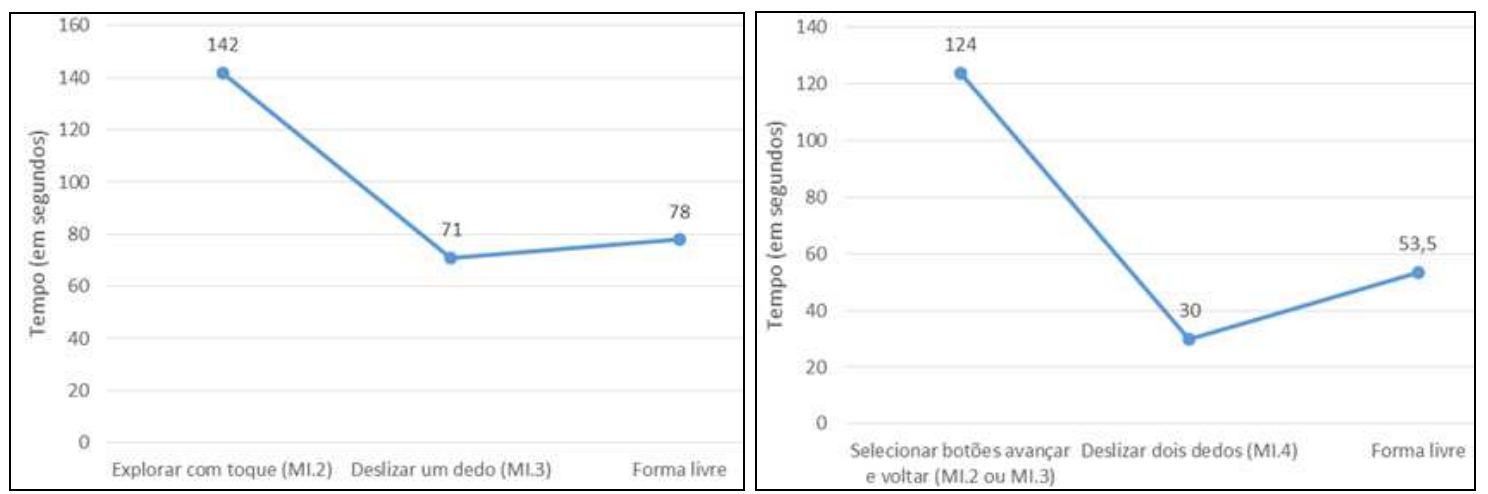

Figura 3. (a) Média de Tempo Teste A; (b) Média de Tempo Teste B

Já o MI3 foi mais rápido para a maioria, porque eles não esperavam pela leitura completa das frases, pois já tinham escutado essas frases nas tarefas anteriores. A maioria dos participantes, inclusive, optou pelo MI3, ao realizar a tarefa da Forma Livre.

\section{Resultados do Grupo B (baixa visão)}

Em relação ao Grupo B, pudemos notar que eles tiverem sucesso total nas tarefas, com $100 \%$ de acertos em ambos os testes A e B. Apesar do número limitado de participantes desse grupo, apenas dois, pôde-se notar que eles não possuem dificuldades para realizar nenhuma das tarefas. A média dos tempos foi satisfatória para ambos os testes A e B. A tarefa 2 do Teste B "navegar entre as perguntas", com MI4, foi a mais rápida.

Em relação às preferências do Teste $\mathrm{A}$, um dos participantes com baixa visão utilizou o MI2 e o outro acabou não utilizando nenhum dos mecanismos solicitados (MI2 ou MI3). Este participante utilizou o MI1 que significa selecionar o elemento na tela. Como eles conseguem enxergar a tela com alto contraste, torna-se mais fácil para eles ir direto ao elemento e selecioná-lo com dois toques na tela. Em relação às preferências do Teste $B$, também ouve uma divergência, enquanto um participante preferiu utilizar o MI1, via botões, o outro preferiu utilizar o MI4. De qualquer modo, ambos os Mis fora úteis para este perfil de usuário.

Nos dois testes os participantes do Grupo B preferiram realizar as tarefas com o TalkBack ativado e contraste de cores. Observamos também que o mais prático para eles é utilizar o MI1 para selecionar os elementos ao invés do MI2 e MI3, já que conseguem enxergar e inclusive ler as tarefas com fonte aumentada. 


\section{Conclusões e Trabalhos Futuros}

Neste trabalho apresentamos um sistema de avaliação didática acessível e portátil, denominado QUIZ. O design desse sistema seguiu as orientações do Design Universal e foi baseado nas diretrizes de usabilidade e acessibilidade da plataforma Android.

O QUIZ foi avaliado por alunos com deficiência visual, cegos e baixa visão, para verificar sua viabilidade como ferramenta educacional. Os testes permitiram aos alunos cumprir tarefas e, em seguida, graduá-las de acordo com um grau de dificuldade. As lições aprendidas com esta pesquisa são: (1) o tutorial foi essencial para ensinar os alunos a usarem os mecanismos de interação (MIs) para navegação no aplicativo; (2) não houve erros na tarefa "Forma Livre", o que nos leva a crer que a prática, adquirida a partir das primeiras atividades, os ajudaram a melhorar o domínio dos MIs sobre a tela touchscreen; (3) alunos com baixa visão preferem utilizar o tablet com o TalkBack ativado; (4) alunos variam em familiaridade com o tablet, o que afetou a velocidade com que usaram o aplicativo; (5) o mecanismo de interação MI3 "deslizar um dedo para direita ou esquerda" é o preferido dos participantes cegos, portanto, futuros aplicativos, com as mesmas características do QUIZ, devem se basear nele para facilitar o uso por este perfil de usuário.

Trabalhos futuros incluem testes com um número maior de participantes em situações reais de ensino.

\section{Referências}

Albernaz, N.H.C.; Elia, M.F.; Borges, J.A.S. Digitavox: Curso de digitação com acessibilidade para deficientes visuais. Anais do XXII Simpósio Brasileiro de Informática na Educaçção (SBIE) - Workshop de Informática na Escola (WIE).

Bazon, F. V. M., (2012) "Escolarização de Alunos com Deficiência Visual: Elaboração e Utilização de Materiais Didáticos como Recursos Pedagógicos Inclusivos.” XVI ENDIPE - Encontro Nacional de Didática e Práticas de Ensino.

DOSVOX - Projeto. Disponível em <http://intervox.nce.ufrj.br/dosvox/>. Acesso em maio de 2015.

Filho, A. G., de Oliveira, A., \& de Souza, F. D. F. (2012). "Utilização de Interfaces Multi-Touch em Ambientes Virtuais de Aprendizagem para Ampliação da Acessibilidade de Deficientes Visuais". In Anais do $23^{\circ}$ Simpósio Brasileiro de Informática na Educação (SBIE), Rio de Janeiro-RJ, 2012.

Filho, M., \& Waechter, H. (2013). Tecnologias Assistivas Presentes no Tablet e Seu Potencial Para Uma Educação Inclusiva de Pessoas com Deficiência Visual. Revista Brasileira De Tradução Visual, vol. 15, n.15.

Henrich M., Mouza, C. (2014) "Use of Tablet Computers and Mobile Apps to Support $21^{\text {st }}$ Century Learning Skills". In: An H.; Alon, S.; Fuentes, D. (Org) "Tablets in K12 Education: Integrated Experiences and Implications: Integrated Experiences and Implications”, IGI Global, 2014.

Machado, D. R., Machado, R. P., Conforto, D. (2014) Dispositivos móveis e usuários cegos: recomendações de acessibilidade em discussão, Nuevas Ideas en Informática Educativa TISE 2014. 
Menezes, M.E.; Kruger-Dissenha, S.E.; Almeida, M.E.B. (2013) "Pesquisas de professores sobre práticas educativas com os laptops UCA na Escola Pública”. Anais do II Congresso Brasileiro de Informática na Educação (CBIE).

Nielsen. J.; Badiu, R. (2012). Mobile Usability. New Riders Press.

ORGANIZAÇÃO MUNDIAL DA SAÚDE (OMS). CID-10 - Classificação estatística internacional de doenças e problemas relacionados à saúde: $10^{\mathrm{a}}$ revisão. 6. ed. São Paulo: Centro Colaborador da OMS para a Classificação de Doenças em Português/EDUSP; 2001.

Real, L. M. C., Tavares, M. N. R., \& dos Santos Picetti, J. (2013). Formação de Professores para o Uso Educacional de Tablets no Ensino Médio: possíveis mudanças na prática pedagógica. Anais do II Congresso Brasileiro de Informática na Educação (CBIE), Campinas-SP, 2013.

Rosito, M.; Scariot, A.O. Desenvolvendo Checklists para a Produção de Material Didático Digital Acessível para Alunos com Deficiência Visual (2012). Anais do $23^{\circ}$ Simpósio Brasileiro de Informática na Educação (SBIE ).

Santos, L.G.; Bandeira, A.L.M.; Pansanato, L.T.E.; Paiva, D.M.B. (2012) Recursos de Acessibilidade para Auxiliar a Navegação de Estudantes Cegos em um Editor de Diagramas. Anais do $23^{\circ}$ Simpósio Brasileiro de Informática na Educação (SBIE 2012), Rio de Janeiro, novembro, 2012.

Silva, C. M. F., de Almeida, D. R., Bernardes, R. R., Bazzano, F. C. O., Filho, M. M., de Toledo Magalhães, C. H., \& Von Atzingen, D. A. N. C. (2013). Desempenho escolar: interferência da acuidade visual. Brasileira de, 72(3), 168-71.

Silveira, H.M.; Martini, L.C. (2011) Extensão de Recursos e Plano de Avaliação do MATVOX: aplicativo matemático programável de apoio para deficientes visuais. Anais do XXII Simpósio Brasileiro de Informática na Educaçção (SBIE) - Workshop de Informática na Escola (WIE), Aracaju, novembro de 2011.

Sá., E. D., de Campos, I. M., e Silva, M. B. C., (2007) "Formação Continuada a Distância de Professores para o Atendimento Educacional Especializado Deficiência Visual", http://portal.mec.gov.br/seesp/arquivos/pdf/aee_dv.pdf

Shuler, C. (2009) Pockets of Potential: Using Mobile Technologies to Promote Children's learning", New York: The Joan Ganz Cooney Center at Sesame Workshop, janeiro de 2009.

Venâncio, V., Telles, E. D. O., Franco, J. F., Aquino, E., Ficheman, I. K., \& Lopes, R. D. D. (2008). "UCA-Um computador por Aluno: um relato dos protagonistas do Piloto de São Paulo". Anais XIX Simpósio Brasileiro de Informática na Educação, Fortaleza-CE, novembro, 2008.

WHO - WORLD HEALTH ORGANIZATION. Visual impairment and blindness, Fact Sheet $\mathrm{N}^{\circ}$ 282. Disponível em: http://www.who.int/mediacentre/factsheets/fs282/en/. Acesso em: 15 de abril de 2015. 